\title{
The Protective Effect of Amifostine on Radiation-Induced Proctitis: Systemic Versus Topical Application
}

\author{
Cem Uzal' ${ }^{1}$ Atakan Sezer ${ }^{2}$, Ufuk Usta ${ }^{3}$, Necdet Süt ${ }^{4}$, Alaattin Özen ${ }^{1}$, Mehmet Ali Yağcı \\ ${ }^{1}$ Department of Radiation Oncology, Faculty of Medicine, Trakya University, Edirne, Turkey \\ ${ }^{2}$ Department of Surgery, Faculty of Medicine, Trakya University Edirne, Turkey \\ ${ }^{3}$ Department of Pathology, Faculty of Medicine, Trakya University Edirne, Turkey \\ ${ }^{4}$ Department of Biostatistics, Faculty of Medicine, Trakya University, Edirne, Turkey
}

\section{ABSTRACT}

Objective: The aim of the study was to evaluate the radioprotective efficacy of intrarectal administration of amifostine in radiation-induced proctitis compared to intraperitoneal administration.

Materials and Methods: Thirty-two Sprague-Dawley rats were randomly divided into four groups: Control (CONT), irradiation alone (RT), intraperitoneal amifostine plus irradiation (IPAMI), and intrarectal amifostine plus irradiation (IRAMI). The rats in the RT, IPAMI and IRAMI groups were irradiated individually with a single dose of $17.5 \mathrm{~Gy}$ to the pelvis. Amifostine was administered by the intraperitoneal ( $200 \mathrm{mg} / \mathrm{kg}$ ) or intrarectal ( $2000 \mathrm{mg} / \mathrm{kg}) \mathrm{route}$ before irradiation. Histopathologic analysis of the rectum was performed 14 days after irradiation.

Results: Significant radiation damage appeared in all histopathologic parameters and was reduced by amifostine. Pretreatment with IPAMI significantly reduced the inflammatory infiltrate in the lamina propria $(p=0.021)$, cryptitis $(p=0.002)$ and crypt abscess $(p=0.015)$. However, the protective effect of IRAMI was significant for all parameters with equal or higher significance than IPAMI, including the eosinophil leucocytes count ( $p=0.02$ ), and distortion of the crypts $(p=0.008)$, and was also significant for regenerative/reparative atypia $(p=0.013)$.

Conclusion: Intrarectal high dose topical administration of amifostine is more effective in the prevention of radiation-induced proctitis compared to its intraperitoneal systemic administration.

Key Words: Amifostine, proctitis, irradiation, radioprotection

Received: 05.10.2010 Accepted: 28.02.2011

\section{Introduction}

Radiation therapy (RT) is an important treatment modality in pelvic malignancies. One of the most important complications of pelvic RT is proctitis. Over $75 \%$ of patients suffer from acute radiation proctitis (ARP) manifesting as diarrhea, tenesmus, abdominal cramps, pain, and hematochesia (1). These side effects can cause treatment interruption, and result in decreased tumor control. Acute effects in the rectum are usually mild and transient, and mostly subside after completion of RT, but, in some cases RT can be a cause of severe chronic complications, developing in $5 \%$ to $20 \%$ of the patients within 5 years after treatment.

To date, there has been no good definition of the underlying mechanism of ARP and preventive and therapeutic intervention is controversial (2). The major features of acute toxicity in histopathologic examination of the rectum are inflammation and epithelial damage of the mucosa, whereas those of late injury are extensive submucosal fibrosis, ulcer formation, and necrosis (3). There is experimental and clinical data suggesting that acute damage to intestinal mucosa and the vascular endothelium precede late damage, depending also on the total dose, irradiated volume and protocol of RT $(4,5)$. There are many agents used in the medical treatment of ARP in clinical practice, such as bile-acid sequestering resins (sucralfate), oral nonsteroidal anti-inflammatory agents (sulfasalazine), and oral or rectal corticosteroids $(1,2,6,7)$. However, they are not effective enough and their benefit is limited (6). Prophylactic use of radioprotectants prior to fractionated irradiation may be an alternative strategy for additional reduction of rectal damage in patients with pelvic malignancies. The effect of ionizing radiation on cells is primarily mediated through the action of free radicals, which can cause damage to DNA, proteins, and lipids. Furthermore, antioxidative defense mechanisms initiated by irradiation are responsible for much of the radiation-induced damage $(8,9)$.

Amifostine (2-[(3-aminopropyl) amino] ethanethiol dihydrogen phosphate; WR-2721) is a prodrug that is converted in vivo by alkaline phosphatase to an active sulfhydryl compound (WR-1065). This substance selectively protects normal cells from radiation toxicity by scavenging free radicals, by donating hydrogen ions to free radicals, and by depleting oxygen, thus diminishing the indirect oxidative effect of ionizing radiation on cellular components, especially on DNA. Previous 
studies have showed substantial radioprotective effects of amifostine on the rectal mucosa by systemic administration $(9,10)$. Accordingly, the topical administration of amifostine on the rectal mucosa may be a possible strategy to permit safe dose escalation of the drug and prevention of the side effects (such as hypotension, nausea, vomiting, allergic and skin reactions, etc.), which can occur with systemic administration (11).

The aim of the present study was therefore to evaluate the radioprotective effects of high dose intrarectal administration of amifostine on irradiated rectum and to compare them to those afforded by its systemic intraperitoneal administration, in a standard rat ARP model, using histopathologic parameters.

\section{Materials and Methods}

\section{Animals and experimental design}

Our study protocol was reviewed and approved by the Animals' Ethical Committee of Trakya University. All rats were treated in accordance with the "Guide for the Care and Use of Laboratory Animals" prepared by the National Academy of Sciences and published by the National Institutes of Health (NIH Publication 85-23, revised 1985). Thirty-two SpragueDawley rats weighing 250 to $300 \mathrm{~g}$ were included in the experiment. The rats were subjected to one week of preliminary conditioning. During that period and the follow-up, they received standard pelleted rat chow (Yem Kurumu, Istanbul, Turkey) and water ad libitum. They were housed in a temperature $\left(21 \pm 2^{\circ} \mathrm{C}\right)$ and humidity $(55 \pm 2 \%)$ controlled environment, with two rats per cage, and with a 12-hour light/12-hour dark cycle.

The rats were randomly assigned into four groups, for the following procedures:

- Group 1: Control (CONT)-injected with normal saline (200 $\mathrm{mg} / \mathrm{kg}$ ) by the intraperitoneal method 30 minutes before a sham irradiation.

- Group 2: Irradiation alone (RT)-injected with normal saline $(200 \mathrm{mg} / \mathrm{kg}$ ) by the intraperitoneal method 30 minutes before irradiation.

- Group 3: Intraperitoneal amifostine (Ethyol ${ }^{\circledR} 500 \mathrm{mg} / 10 \mathrm{~mL}$ vial, Er-Kim İlaç, Istanbul, Turkey) before irradiation (IPAMI)injected with amifostine $(200 \mathrm{mg} / \mathrm{kg}, 500 \mathrm{mg}$ dissolved in $10 \mathrm{~mL}$ saline solution) by the intraperitoneal method 30 minutes before irradiation (11).

- Group 4: Intrarectal amifostine before irradiation (IRAMI)administered with amiphostine at a level of $2000 \mathrm{mg} / \mathrm{kg}$ by the intrarectal method 30 minutes before irradiation. The solution was reconstituted in normal saline solution to bring the volume of enema to $2.5 \mathrm{~mL}$ (11).

All experimental procedures were performed on anesthetized rats. Each rat was anesthetized using $5 \mathrm{mg} / \mathrm{kg}$ of xylazine (Rompun, Bayer Türk Kimya Sanayi Limited Şirketi, Istanbul, Turkey) and $30 \mathrm{mg} / \mathrm{kg}$ of ketamine hydrochloride (Ketalar, Pfizer Illaçları Limited Şirketi, Istanbul, Turkey) intramuscularly prior to irradiation. The follow-up period was 14 days. During follow-up, all rats were monitored by the veterinary care staff.

\section{Irradiation}

The rats in the IPAMI, IRAMI and RT groups were irradiated individually with a single dose of $17.5 \mathrm{~Gy}$ to the pelvis at $80 \mathrm{~cm}$ SSD, using a ${ }^{60} \mathrm{Co}$ treatment unit (Cirus, cis-Bio Int., Gif Sur Yvette, France) (12). The dose rate was approximately $1.07 \mathrm{~Gy} / \mathrm{min}$. The rats were anesthetized and then fixed onto a $5 \times 20 \times 30 \mathrm{~cm}$ polystyrene foam treatment couch in the prone position. Correct positioning of the fields was controlled for each individual rat using a therapy simulator (MecasertoSimics, Paris, France). Special dosimetry was done for a postero-anterior $5 \times 5 \mathrm{~cm}$ open pelvic field at a depth of $1.5 \mathrm{~cm}$. The dosage homogeneity across the entire thickness $(3 \mathrm{~cm})$ was $\pm 7 \%$. After irradiation, the animals were closely observed until recovery from anesthesia. The CONT group received an equal field sham irradiation.

\section{Euthanasia}

Rats from each experimental group were euthanized on day 14 after the irradiation or sham irradiation. These observation times are representative of the early phase in the development of radiation enteropathy in our model system (1315). Euthanasia was performed by cardiac exsanguination via ketamine and xylazine anesthesia. The rectal specimens were excised for histopathologic evaluation.

\section{Histopathologic analysis}

All rectal segments were fixed in $10 \%$ neutral buffered formaldehyde, and representative parts were embedded in paraffin after routine processing of the tissues. Five micrometer sections were obtained from each paraffin block and stained with hematoxylene and eosin (Figure 1). Slides were examined twice by the same pathologist under a light microscope (Nikon Eclipse E600) in a blinded manner. Inflammatory infiltrate in the lamina propria, infiltration of crypt epithelium by leucocytes (cryptitis), distortion of the crypts and regenerative/reparative atypia of the epithelial cells were examined, and measured from zero to three degrees according to the severity of the lesions-where zero refers to no lesions: one, a mild lesion; two, a moderate lesion; and three, a severe lesion. A crypt abscess was noted as being either positive or negative for each slide. Eosinophil leucocytes were counted in the lamina propria in five consecutive high power fields (HPF), and the sum was divided by five for each slide.

\section{Statistical analysis}

Results are expressed as medians (min-max) or numbers (percentages). The differences measuring the parameters among the four groups were analyzed using the KruskalWallis test, and then the Mann-Whitney $U$ test with Bonferroni correction was used when significant results were obtained. Categorical variables were compared using the Chi-square test. A p value $<0.05$ was considered as statistically significant. The data were analyzed using Statistica 7.0 (StatSoft Inc. Tulsa, OK, USA).

\section{Results}

No mortality was observed in any group. All animals were evaluated using the same microscopic procedures.

Histopathologic analyses were made on 32 rats. All histopathologic parameters were significantly different among the 

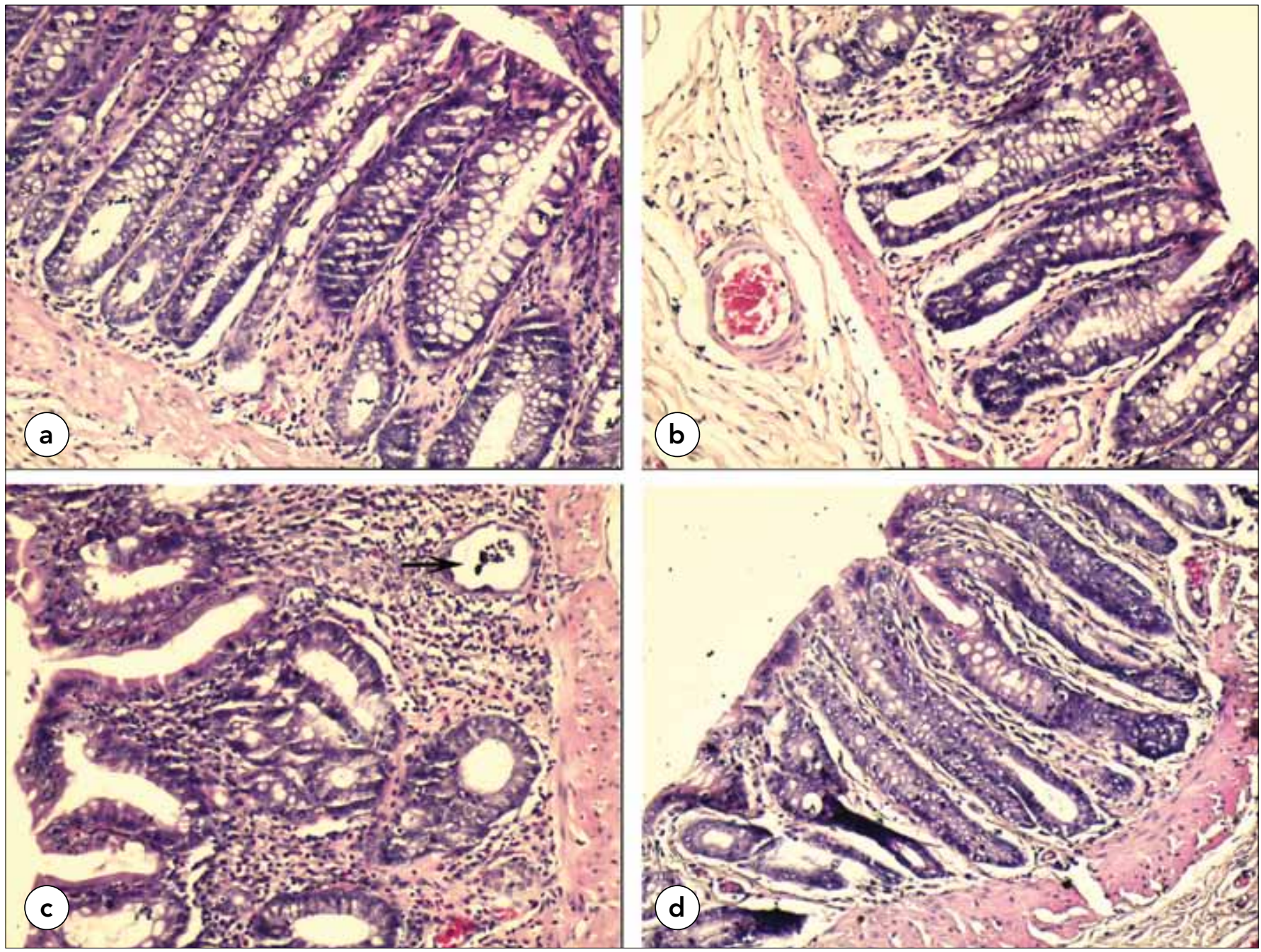

Figure 1. Normal microscopic appearance of the rectal mucosa of the control group (a) and the intrarectal amifostine group (b). There is prominent mucosal inflammation and severe crypt distortion in the irradiation alone group. There is also crypt abscess in a distorted crypt (arrow) (c). In the intraperitoneal amifostine group mild distortion and mild mucosal inflammation can be observed (d). (HEx100)

groups $(p<0.001)$. They significantly worsened after irradiation compared to the controls, most of which were significantly improved by intraperitoneal amifostine administration, and this was also the case for all parameters with intrarectal administration $(p<0.05)$ (Figure 1). The findings are summarized in Tables 1, 2 and 3.

Inflammatory infiltrate in the lamina propria significantly increased in the RT group, compared with the CONT $(p<0.001)$, IPAMI $(p=0.021)$ and IRAMI groups $(p=0.005)$. Additionally, the degree of this damage was higher in the IPAMI group than the CONT group $(p=0.01)$. There was no significant difference in the CONT versus the IRAMI group ( $p>0.05)$.

An increased eosinophil leucocytes count in the lamina propria was observed in the RT $(p=0.001)$ and IPAMI $(p=0.018)$ groups compared with the CONT group. Accordingly, there was no benefit for the IPAMI versus the RT group $(p>0.05)$. Meanwhile the IRAMI group eosinophil leucocytes count significantly decreased compared to the RT and IPAMI groups $(p=0.002$ and $p=0.046$ respectively), while there was no significant difference in the IRAMI versus the CONT group ( $p>0.05)$.

Radiation-induced infiltration of crypt epithelium by leucocytes (cryptitis) and crypt abscess was significantly worse in the RT group compared with the CONT $(p<0.001$ and $p=0.001)$, IPAMI $(p=0.002$ and $p=0.015)$ and IRAMI groups $(p=0.002$ and $p=0.015)$. There was no significant difference in the CONT group versus the IPAMI or IRAMI groups, similarly for the IPAMI versus IRAMI groups ( $p>0.05)$. The distortion of the crypts was significantly better in the CONT group compared to the RT $(p<0.001)$, IPAMI $(p=0.004)$ and IRAMI groups $(p=0.003)$. IRAMI significantly reduced the distortion of the crypts compared to the RT group $(p=0.008)$ which was not significant for the IPAMI versus the RT group ( $p>0.05)$.

The other histologic change was the regenerative/reparative atypia of the epithelial cells. Significant damage was observed in the RT, IPAMI and IRAMI groups compared to the CONT group ( $p<0.001, p=0.010$ and $p=0.027$ respectively). IRAMI significantly reduced this damage compared to the RT 
Table 1. The frequency of rectal histopathologic damage for each group according to the grade of damage

\begin{tabular}{|c|c|c|c|c|c|}
\hline & Grade & $\begin{array}{l}\text { CONT } \\
(n=8)\end{array}$ & $\begin{array}{c}\mathrm{RT} \\
(n=8)\end{array}$ & $\begin{array}{l}\text { IPAMI } \\
(n=8)\end{array}$ & $\begin{array}{l}\text { IRAMI } \\
(n=8)\end{array}$ \\
\hline Inflammatory infiltrate & 0 & $8(100 \%)$ & 0 & $3(37.5 \%)$ & $5(62.5 \%)$ \\
\hline \multirow[t]{3}{*}{ in the lamina propria } & 1 & 0 & $2(25 \%)$ & $3(37.5 \%)$ & $2(25 \%)$ \\
\hline & II & 0 & $4(50 \%)$ & $2(25 \%)$ & $1(12.5 \%)$ \\
\hline & III & 0 & $2(25 \%)$ & 0 & 0 \\
\hline \multirow[t]{4}{*}{ Cryptitis } & 0 & $8(100 \%)$ & 0 & $6(75 \%)$ & $6(75 \%)$ \\
\hline & I & 0 & $5(62.5 \%)$ & $2(25 \%)$ & $2(25 \%)$ \\
\hline & II & 0 & $2(25 \%)$ & 0 & 0 \\
\hline & III & 0 & $1(12.5 \%)$ & 0 & 0 \\
\hline \multirow[t]{4}{*}{ Distortion of the crypts } & 0 & $8(100 \%)$ & 0 & $2(25 \%)$ & $2(25 \%)$ \\
\hline & I & 0 & $2(25 \%)$ & $3(37.5 \%)$ & $5(62.5 \%)$ \\
\hline & II & 0 & $2(25 \%)$ & $2(25 \%)$ & $1(12.5 \%)$ \\
\hline & III & 0 & $4(50 \%)$ & $1(12.5 \%)$ & 0 \\
\hline \multirow[t]{4}{*}{ Regenerative/reparative atypia } & 0 & $8(100 \%)$ & 0 & $3(37.5 \%)$ & $4(50 \%)$ \\
\hline & I & 0 & $3(37.5 \%)$ & $3(37.5 \%)$ & $3(37.5 \%)$ \\
\hline & II & 0 & $4(50 \%)$ & $2(25 \%)$ & $1(12.5)$ \\
\hline & III & 0 & $1(12.5 \%)$ & 0 & 0 \\
\hline
\end{tabular}

Table 2. Rectal histopathological damage for each group according to the eosinophil leucocytes count or presence of crypt abscess

\begin{tabular}{|lcccc|}
\hline & $\begin{array}{c}\text { CONT } \\
(\mathbf{n}=8)\end{array}$ & $\begin{array}{c}\text { RT } \\
(\mathbf{n = 8})\end{array}$ & $\begin{array}{c}\text { IPAMI } \\
(\mathbf{n}=\mathbf{8})\end{array}$ & $\begin{array}{c}\text { IRAMI } \\
(\mathbf{n}=\mathbf{8})\end{array}$ \\
\hline Eosinophil leucocytes (count) & $15(4-36)$ & $62.5(42-112)$ & $44.5(11-107)$ & $17.5(6-61)$ \\
Crypt abscess (presence) & $0(0 \%)$ & $7(87.5 \%)$ & $2(25 \%)$ & $2(25 \%)$ \\
\hline Median (min-max); $\mathrm{n}(\%)$ & & & \\
\hline
\end{tabular}

Table 3. Significance of differences as $p$ values in histopathologic parameter changes among the groups

\begin{tabular}{|c|c|c|c|c|c|c|}
\hline & CONT-RT & $\begin{array}{l}\text { CONT- } \\
\text { IPAMI }\end{array}$ & $\begin{array}{l}\text { CONT- } \\
\text { IRAMI }\end{array}$ & $\begin{array}{l}\text { RT- } \\
\text { IPAMI }\end{array}$ & $\begin{array}{l}\text { RT- } \\
\text { IRAMI }\end{array}$ & $\begin{array}{l}\text { IPAMI- } \\
\text { IRAMI }\end{array}$ \\
\hline $\begin{array}{l}\text { Inflammatory infiltrate } \\
\text { in lamina propria }\end{array}$ & $<0.001$ & 0.010 & 0.064 & 0.021 & 0.005 & 0.330 \\
\hline $\begin{array}{l}\text { Eosinophil leucocytes } \\
\text { (count) }\end{array}$ & 0.001 & 0.018 & 0.430 & 0.208 & 0.002 & 0.046 \\
\hline Cryptitis & $<0.001$ & 0.143 & 0.143 & 0.002 & 0.002 & 1.0 \\
\hline $\begin{array}{l}\text { Crypt abscess } \\
\text { (presence) }\end{array}$ & 0.001 & 0.143 & 0.143 & 0.015 & 0.015 & 1.0 \\
\hline Distortion of the crypts & $<0.001$ & 0.004 & 0.003 & 0.063 & 0.008 & 0.461 \\
\hline Regenerative/reparative atypia & $<0.001$ & 0.010 & 0.027 & 0.052 & 0.013 & 0.593 \\
\hline
\end{tabular}

group $(p=0.013)$, but this significance was borderline for the IPAMI group $(p=0.052)$.

\section{Discussion}

We present two important findings regarding amifostine and radiation-induced acute rectal damage. First, amifostine significantly ameliorated the radiation-induced acute rectal damage either by intrarectal or intraperitoneal administration.
Second, our findings show that intrarectal administration of amifostine is superior to intraperitoneal administration.

Acute injury in the rectum is characterized by loss of epithelial cells, due to crypt stem cell injury, with inflammatory cell infiltrate, particularly of eosinophils; and finally the mucosa may ulcerate $(16,17)$. The pathogenesis of these changes is still not clearly understood. Acute changes occur during and immediately after irradiation in the form of hyperemia, edema, and extensive inflammatory cell infiltration of the mucosa 
(18). Radiation-induced injury is explained by cytotoxic effects of free radicals, damaging the endothelial cells of intestinal capillaries (19). In a sequential clinicopathologic study during pelvic radiotherapy, examination of the biopsies demonstrated that all histologic parameters exhibited maximal values at two weeks after the initiation of RT, but regressed from two to six weeks despite continued daily RT and worsening clinical symptoms (20).

Since the active metabolite of the drug (WR-1065) is absorbed in a greater concentration in normal tissues compared to tumor tissues, amifostine has a selective radioprotection property (21). This differential uptake of free thiol is a result of differences in the microenvironment at the tissue level, such as lower capillary alkaline phosphatase activity, lower $\mathrm{pH}$, and poorer vascularity in tumor tissues than normal tissues, resulting in the slow entry of free thiol into tumor masses. Several studies have been conducted on the cytoprotective effect of amifostine against radiation-induced toxicity in pelvic irradiated areas $(9,10,22,23)$. Pre-treatment amifostine administered either by intracolonic or intraperitoneal instillation demonstrated a radioprotective effect in the murine colon and the rectum. France et al. (24) showed that double-blind histologic evaluation of colons from irradiated rats treated with intracolonic WR 2721 demonstrated a radioprotective effect with a dose modifying factor of 1.8 when compared with controls. In another study by lto et al. (25), the authors concluded that WR-2721 is indeed effective in protection against late damage from large single doses of radiation to the rectum as measured histologically and also improves the long-term survival of the mice, although the target cells for this damage are not known. Recently, Katsanos et al. (26) stated that amifostine given subcutaneously can lower the risk of acute severe radiation colitis in a randomised phase II exploratory clinical trial. They revealed that acute radiation colitis and grade IV radiation colitis did not occur in the amifostine arm but developed in $17.4 \%$ of patients who did not receive amifostine prophylaxis $(p=0.05)$.

As has been reported in the literature, the topical application of amifostine has been challenging, because its intravenous or subcutaneous application is linked with systemic toxicity (21). The lack of systemic absorption when applied topically to the rectum prevents side-effects, while the risk of delivery of the drug to the tumor is removed and potential tumor protection is avoided $(8,22)$. Moreover, as reported by Ben-Josef et al. $(22,23)$ topical amifostine reaches high concentrations in the rectal wall. The study by Kouloulias et al. (9) clearly demonstrated the feasibility and tolerability of this approach. There were no issues regarding their patients' ability to retain the daily enema in the supine, sitting, or upright position and no systemic toxicity was reported. Intrarectal administration of amifostine in 29 patients with localized prostate cancer showed that higher doses (1500$2500 \mathrm{mg}$ ) of amifostine produced a statistically significant reduction in severity of radiation-induced symptoms compared with lower doses (500-1000 mg) (23). Another study using low dose (100-450 mg) amifostine showed no differences in symptoms (27).
The cytoprotective effect of intrarectal amifostine against radiation-induced acute rectal mucosal toxicity was evaluated in several clinical studies. Kouloulias et al. (8) suggested that intrarectal administration of amifostine exhibits a cytoprotective efficacy in acute radiation-induced rectal mucositis in a phase II study. The same authors concluded that intrarectal administration of amifostine expressed a superior cytoprotective efficacy in acute radiation rectal mucositis in a later study comparing the cytoprotective effect of subcutaneous and intrarectal route of amifostine against acute radiation toxicity (9). Kouvaris et al. (10) established that amifostine was well tolerated and showed a significant cytoprotective efficacy in acute radiation-induced rectal mucositis in terms of symptomatic and objective end-points. The protective effect of increased concentrations of intrarectal amifostine was also reported in other studies $(28,29)$.

Inflammatory infiltrate in the lamina propria is one of the important acute radiation injuries in the rectum (30). In the present study, it was ameliorated with amifostine, and intrarectal administration further rendered it at the control level. Another prominent aspect is the large number of eosinophils in inflammatory reactions. The importance of this occurrence is unclear. It is possible that reduced epithelial barrier function allows access of antigens to subepithelial tissues, which induce a reactive eosinophilic inflammatory reaction (20). Trier et al. (30) also defined this homogeneous eosinophilic material in the submucosal tissue, as suggestive of edema fluid, in a pioneer prospective study. We showed that the increase of eosinophil leucocytes in the lamina propria was prevented only by intrarectal administration of amifostine.

Although crypt abscess formation is most probably preceded by cryptitis, both of these changes were graded separately since cryptitis is reported to be more prevalent than crypt abscesses, and on many occasions the two changes did not occur simultaneously $(16,18,20,30)$. In their sequential clinicopathologic study, Hovdenak et al. (20) found that inflammatory changes were prominent and consisted of cryptitis (migration of leukocytes through the crypt wall), crypt abscesses, inflammatory cell infiltration in the surface epithelium and lamina propria, and a striking accumulation of eosinophilic granulocytes. In the present study, crypt abscess formation and cryptitis were observed synchronously and the protective effect of intrarectal amifostine was similar to intraperitoneal amifostine within these parameters. Moreover, there was no significant difference between the control and amifostine administered groups. With regard to the distortion of the crypts, the amelioration was significant with intrarectal administration, but not so with intraperitoneal administration.

The importance of atypical nuclei and atypical mitoses still needs to be explained. An increased incidence of adenocarcinoma development after therapeutic irradiation has been observed in some researches (31). However, it was also found in a clinical study that the rectal glands (crypts) exhibited nuclear migration toward the luminal pole of the cells, atrophy, and distortion with loss of goblet cells and/or of complete glands, similar to our study (20). We also showed that intrarectal amifostine significantly reduced the regenerative/reparative atypia of the epithelial cells induced by RT, but this significance 
was borderline for intraperitoneal amifostine. However, atypia still remained higher in both administrations of amifostine compared to the control group.

In conclusion, this is the first animal study that compares two different administration routes of amifostine. Additionally, we showed that high dose intrarectal amifostine administration significantly ameliorated the radiation-induced acute rectal damage for all histopathologic parameters. On the other hand, one must keep in mind that the systemic route surpasses topical administration in terms of cost-effectiveness, although topical administration is better than the systemic route for protective effectiveness. It is clearly seen that, to achieve success with intrarectal administration, it is necessary to use ten-fold larger dose of amifostine than the dose used through the systemic route, resulting in a ten-fold increase in the total cost. This issue can be important particularly for developing countries. Additionally, this study is limited because of lack of immunohistopathological assesement of intestinal tissue and lack of clinicopathological assessment of findings such as diarrhea. However, since rectal injuries caused by pelvic RT continue to be a major clinical side-effect, it would be worthwhile to study the effects of intrarectal amifostine in radiation-treated patients with pelvic malignancies in regard to radioprotection, as well as whether there would be a negative effect on longterm tumor control.

\section{Conflict of Interest}

No conflict of interest was declared by the authors.

\section{References}

1. Zimmermann FB, Feldmann HJ. Radiation proctitis. Clinical and pathological manifestations, therapy and prophylaxis of acute and late injurious effects of radiation on the rectal mucosa. Strahlenther Onkol 1998;174 Suppl 3:85-9.

2. Hong JJ, Park W, Ehrenpreis ED. Review article: current therapeutic options for radiation proctopathy. Aliment Pharmacol Ther 2001;15:1253-62. [CrossRef]

3. Lundby L, Overgaard J, Laurberg S. Histopathological and morphometric analyses of late rectal injury after irradiation. APMIS 2000;108:216-22. [CrossRef]

4. Dubray BM, Thames HD. Chronic radiation damage in the rat rectum: an analysis of the influences of fractionation, time and volume. Radiother Oncol 1994;33:41-7. [CrossRef]

5. Wang CJ, Leung SW, Chen HC, Sun LM, Fang FM, Huang EY, et al. The correlation of acute toxicity and late rectal injury in radiotherapy for cervical carcinoma: evidence suggestive of consequential late effect (CQLE). Int J Radiat Oncol Biol Phys 1998;40:85-91. [CrossRef]

6. Korkut C, Asoglu O, Aksoy M, Kapran Y, Bilge H, Kiremit-Korkut $\mathrm{N}$, et al. Histopathological comparison of topical therapy modalities for acute radiation proctitis in an experimental rat model. World J Gastroenterol 2006;12:4879-83.

7. Sanguineti G, Franzone P, Marcenaro M, Foppiano F, Vitale V. Sucralfate versus mesalazine versus hydrocortisone in the prevention of acute radiation proctitis during conformal radiotherapy for prostate carcinoma, A Randomized Study. Strahlenther Onkol 2003;179:464-70.

8. Kouloulias VE, Kouvaris JR, Pissakas G, Kokakis JD, Antypas C, Mallas $E$, et al. A phase ii randomized study of topical intrarectal administration of amifostine for the prevention of acute radiation-induced rectal toxicity. Strahlenther Onkol 2004;180:557-62 [CrossRef].
9. Kouloulias VE, Kouvaris JR, Pissakas G, Mallas E, Antypas C, Kokakis JD, et al. Phase II multicenter randomized study of amifostine for prevention of acute radiation rectal toxicity: topical intrarectal versus subcutaneous application. Int J Radiat Oncol Biol Phys 2005;62:486-93. [CrossRef]

10. Kouvaris J, Kouloulias V, Malas E, Antypas C, Kokakis J, Michopoulos $S$, et al. Amifostine as radioprotective agent for the rectal mucosa during irradiation of pelvic tumors. A phase II randomized study using various toxicity scales and rectosigmoidoscopy. Strahlenther Onkol 2003;179:167-74.

11. Damron TA, Spadaro JA, Tamurian RM, Damron LA. Sparing of radiation-induced damage to the physis: Fractionation alone compared to amifostine pretreatment. Int J Radiat Oncol Biol Phys 2000;47:1067-71. [CrossRef]

12. Eifel PJ, Levenback C, Wharton JT, Oswald MJ. Time course and incidence of late complications in patients treated with radiation therapy for FIGO stage IB carcinoma of the uterine cervix. Int J Radiat Oncol Biol Phys 1995;32:1289-300. [CrossRef]

13. Wang J, Zheng $H$, Sung $C C$, Hauer-Jensen $M$. The synthetic somatostatin analogue, octreotide, ameliorates acute and delayed intestinal radiation injury. Int J Radiat Oncol Biol Phys 1999;45:1289-96. [CrossRef]

14. Hauer-Jensen M, Poulakos L, Osborne JW. Effects of accelerated fractionation on radiation injury of the small intestine: a new rat model. Int J Radiat Oncol Biol Phys 1988;14:1205-12. [CrossRef]

15. Langberg CW, Sauer T, Reitan JB, Hauer-Jensen M. Tolerance of rat small intestine to localized single dose and fractionated irradiation. Acta Oncol 1992;31:781-7. [CrossRef]

16. Sharma B, Pandey D, Chauhan V, Gupta D, Mokta J, Thakur SS. Radiation proctitis. Journal Indian Academy of Clinical Medicine 2005;6:146-51

17. Sedgwick DM, Howard GC, Ferguson A. Pathogenesis of acute radiation injury to the rectum. A prospective study in patients. Int J Colorectal Dis 1994;9:23-30. [CrossRef]

18. Pía de la Maza M, Gotteland M, Ramírez C, Araya M, Yudin T, Bunout $D$, et al. Acute nutritional and intestinal changes after pelvic radiation. J Am Coll Nutr 2001;20:637-42.

19. Parks DA, Bulkley GB, Granger DN. Role of oxygen-derived free radicals in digestive tract diseases. Surgery 1983;94:415-22.

20. Hovdenak N, Fajardo LF, Hauer-Jensen M. Acute radiation proctitis: a sequential clinicopathologic study during pelvic radiotherapy. Int J Radiat Oncol Biol Phys 2000;48:1111-7. [CrossRef]

21. Hensley ML, Schuchter LM, Lindley C, Meropol NJ, Cohen GI, Broder G, et al. American Society of Clinical Oncology clinical practice guidelines for the use of chemotherapy and radiotherapy protectants. J Clin Oncol 1999;17:3333-55.

22. Ben-Josef E, Mesina J, Shaw LM, Bonner HS, Shamsa F, Porter AT. Topical application of WR-2721 achieves high concentrations in the rectal wall. Radiat Res 1995;143:107-10. [CrossRef]

23. Ben-Josef E, Han S, Tobi M, Shaw LM, Bonner HS, Vargas BJ, et al. A pilot study of topical intrarectal application of amifostine for prevention of late radiation rectal injury. Int J Radiat Oncol Biol Phys 2002;53:1160-4. [CrossRef]

24. France HG Jr, Jirtle RL, Mansbach CM 2nd. Intracolonic WR 2721 protection of the rat colon from acute radiation injury. Gastroenterology 1986;91:644-50.

25. Ito H, Meistrich ML, Barkley HT Jr, Thames HD Jr, Milas L. Protection of acute and late radiation damage of the gastrointestinal tract by WR-2721. Int J Radiat Oncol Biol Phys 1986;12:211-9. [CrossRef]

26. Katsanos $\mathrm{KH}$, Briasoulis E, Tsekeris P, Batistatou A, Bai M, Tolis $C$, et al. Randomized phase II exploratory study of prophylactic amifostine in cancer patients who receive radical radiotherapy to the pelvis. J Exp Clin Cancer Res 2010;29:68. [CrossRef]

27. Montana GS, Anscher MS, Mansbach CM 2nd, Daly N, Delannes M, Carke-Pearson D, et al. Topical application of WR-2721 to pre- 
vent radiation-induced proctosigmoiditis. A phase I/II trial. Cancer 1992;69:2826-30. [CrossRef]

28. Singh AK, Menard C, Guion P, Simone NL, Smith S, Crouse NS, et al. Intrarectal amifostine suspension may protect against acute proctitis during radiation therapy for prostate cancer: a pilot study. Int J Radiat Oncol Biol Phys 2006;65:1008-13. [CrossRef]

29. Simone NL, Menard C, Soule BP, Albert PS, Guion P, Smith S, et al. Intrarectal amifostine during external beam radiation therapy for prostate cancer produces significant improvements in Quality of Life measured by EPIC score. Int J Radiat Oncol Biol Phys 2008;70:90-5. [CrossRef]

30. Trier JS, Browning TH. Morphologic response of the mucosa of human small intestine to x-ray exposure. J Clin Invest 1966;45:194-204. [CrossRef]

31. Fischer L, Kimose HH, Spjeldnaes N, Wara P. Late progress of radiation-induced proctitis. Acta Chir Scand 1990;156:801-5. 